\title{
Patient safety culture and associated factors: A quantitative and qualitative study of healthcare workers' view in Jimma zone Hospitals, Southwest Ethiopia
}

Sintayehu Daba Wami ${ }^{1 *}$, Amsalu Feleke Demssie ${ }^{2}$, Molla Mesele Wassie ${ }^{3}$ and Ansha Nega Ahmed ${ }^{1}$

\begin{abstract}
Background: Patient safety culture is an important aspect for quality healthcare delivery and is an issue of high concern globally. In Ethiopia health system little is known and information is limited in scope about patient safety culture. Therefore, the aim of this study was to assess the level of patient safety culture and associated factors in Jimma zone Hospitals, southwest Ethiopia.

Methods: Facility based cross sectional quantitative study triangulated with qualitative approaches was employed from March to April 30/2015. Stratified sampling technique was used to select 637 study participants among 4 hospitals. The standardized tool which measures 12 patient safety culture composites was used for data collection. Bivariate and multivariate linear regression analyses were performed using SPSS version 20. Significance level was obtained at $95 \% \mathrm{Cl}$ and $p$-value $<0.05$. Semi structured guide in depth interview was used to collect the qualitative data. Content analysis of the interview was performed.

Results: The overall level of patient safety culture was $46.7 \%$ (95 \% Cl: 43.0, 51.2). Hours worked per week ( $\beta=$ $-0.06,95 \% \mathrm{Cl}:-0.12,-0.001)$, reporting adverse event $(\beta=3.34,95 \% \mathrm{Cl}: 2.12,4.57)$, good communication $(\beta=2$. $78,95 \% \mathrm{Cl}: 2.29,3.28)$, teamwork within hospital $(\beta=1.91,95 \% \mathrm{Cl}: 1.37,2.46)$, level of staffing $(\beta=1.32,95 \%$ Cl: $0.89,1.75)$, exchange of feedback about error $(\beta=1.37,95 \% \mathrm{Cl}: 0.91,1.83)$ and participation in patient safety program ( $\beta=1.3,95 \% \mathrm{Cl}: 0.57,2.03)$ were factors significantly associated with the patient safety culture. The in depth interview indicated incident reporting, resources, healthcare worker attitude and patient involvement as important factors that influence patient safety culture.

Conclusions: The overall level of patient safety culture was low. Working hours, level of staffing, teamwork, communications openness, reporting an event and exchange of feedback about error were associated with patient safety culture. Therefore, interventions of systemic approach through facilitating opportunities for communication openness, cooperation and exchange of ideas between healthcare workers are needed to improve the level of patient safety culture.
\end{abstract}

Keywords: Patient safety culture, Jimma Zone Hospitals, Ethiopia

\footnotetext{
* Correspondence: sintayehudaba2004@gmail.com

'Department of Environmental and Occupational Health and Safety, Institute

of Public Health, University of Gondar, Gondar, Ethiopia

Full list of author information is available at the end of the article
} 


\section{Background}

Patient safety culture is an important aspect for quality of healthcare delivery and is an issue of high concern globally [1-5]. Patient safety culture is the product of individual and group values, attitudes, perceptions, competencies, and patterns of behavior that determine the commitment, the style and proficiency of the health providers' safety management $[2,6,7]$.

In Africa little is known and information are limited in scope about patient safety culture [8,9]. The study in Ethiopia, which used patient safety culture survey tool of Agency of Healthcare Research and Quality, showed very low positive patient safety grade (excellent $7.2 \%$ and very good $20.7 \%$ ) [10].

Adverse events due to unsafe practice in the process of medical care represent a major source of morbidity and mortality globally [11]. Even though evidences are limited, the possibility of patients being harmed in hospitals when receiving medical care is known to be large in African health systems [12, 13].

Establishing a culture of patient safety in the healthcare is essential to improve quality of care and promote patient safety [2, 14-17]. Many factors can be associated with patient safety culture. Organizational culture that encourages reporting and avoids blame and improved communication are reported as important factors to improve patient safety culture [18]. Other studies showed that patient safety culture can be influenced by respondent and hospital characteristics, work area, position, extent of participation in a patient safety program, communication, patient safety management and resources [19-21].

Inappropriate funding and unavailability of critical support systems including strategies, guidelines, tools and patient safety standards remain major worries in Africa. Furthermore, understanding of the problems associated with patient safety culture is hampered by inadequate data [8].

In Ethiopia health system there is also little empirical evidence about patient safety culture and associated factors.

Therefore, this study aimed to assess the level of patient safety culture and find out the associated factors in Jimma zone Hospitals, Southwest Ethiopia.

\section{Methods}

\section{Study design, setting and sample}

A cross sectional quantitative study triangulated with qualitative approaches was employed from March to April 30/2015.

The study was conducted among 4 hospitals, found in Jimma zone, Southwest of Ethiopia. The population being served by the hospitals is estimated to be more than five million including people from border zones and southern part of Sudan. The hospitals deliver health services in many specialty areas. These include gynecology and obstetrics, surgery, pediatrics and child health, internal medicine, ophthalmology, psychiatry, and dentistry.

Healthcare workers in Jimma zone hospitals, who had worked at least for 6 months in the hospitals, were included in this study. Stratified sampling technique was used to select the 637 study participants among 4 hospitals. Healthcare workers were stratified based on the size of hospital. The number of sample points was determined by using proportional allocation formula for each stratum. Then, the required sample sizes were selected by using simple random sampling technique from each stratum. This study targeted clinical and non-clinical staff of hospitals, like physicians, nurses, midwives, psychiatrist, pharmacy, laboratory staff, radiology staff, supervisors, and hospital managers.

For the qualitative study 10 participants were interviewed based on purposive sampling.

\section{Data collection procedure and tool}

Quantitative data was collected through self-administered data collection technique.

The one-to-one in depth interview using a semistructured guide was performed to collect qualitative data.

The questionnaire was originally in English version and it was translated to Amharic and back to English by another translator to check the consistence of message from question. The translation was then reviewed by professional experts. Before starting the actual data collection, $10 \%$ of questionnaires were pre-tested in order to check the validity and consistency of the Amharic translated version of the questionnaire.

The Hospital Survey on Patient Safety Culture (HSOPSC) was used to collect quantitative data on patient safety culture. The tool was designed to assess hospital staff opinions about patient safety culture. It includes 42 items that measure 12 dimensions or composites of patient safety culture. Most items use the 5-point likert response scale of agreement (strongly disagree to strongly agree) or frequency (never to always) [22].

The tool also includes two questions in which respondents provide an overall grade on patient safety in their work area/unit and to indicate the number of events they have reported over the past 12 months (See Additional file 1).

Internal consistency/reliability was checked by calculating Cronbach's alpha for each of the composite to ensure that items with in each composite were consistent. In this study the Cronbach's alpha for the composites ranged from 0.61 to 0.88 . The HSOPSC user's guide indicate that a value of Cronbach's alpha 0.60 or greater is assumed to be acceptable [22]. Therefore, each of the dimensions was found to have an acceptable reliability (See Table 4). 
For the qualitative data semi structured guide in depth interview was conducted. The in depth interview was focused to identify factors influencing patient safety culture (See Additional file 2).

Six Bachelor of Science graduate nurses' data collectors with three supervisors were assigned for quantitative data collection. The qualitative data was collected by the principal investigator.

\section{Measurements}

Level of patient safety culture-measured by the healthcare workers response on the HSOPSC questionnaire in likert scale and percentages of the positive responses (strongly agree and agree or Most of the time and Always) for the 12 patient safety culture dimensions (42 items) were considered as overall level of patient safety culture.

- Scores of $75 \%$ and above considered as good patient safety culture/area of strength.

- Scores between $50 \%$ and $75 \%$ considered as neutral patient safety culture.

- Scores of less than $50 \%$ considered as poor/low patient safety culture/need improvement.

Composite level scores were computed by summation of the items within the composite scales and dividing by the number of items. Negatively worded items were reversed when computing percent positive response.

In this study event means any type of error, mistakes, incident, near misses, accident or deviation regardless of whether or not it results in patient harm.

\section{Data management and analysis}

Quantitative data was checked, edited, coded and entered to Epi-info version 7.00 and exported to Statistical Package for Social Science (SPSS) version 20 for further analysis.

A one-way analysis of variance (ANOVA) was conducted on each of the safety culture dimensions to determine the extent to which composite scores on these safety culture scales are differentiated across hospitals. Linear regression model was fitted to identify factors associated with patient safety culture. The patient safety culture was regressed against the demographic, socioeconomic and systemic factors. Before fitting linear regression model, first the assumptions were checked.

Accordingly, the assumption of linearity checked through both scatter plot and lack of fit test and it was satisfied. The assumption of normality checked by plotting histogram and P-P plots and it was also satisfied. The assumption of homoscedasticity was satisfied by plotting scatter plot of standardized residuals against the standardized predicted values and it was randomly distributed as shown in SPSS output.
The Durbin Watson statistics was used to check the assumption of independence of errors and autocorrelations. The value of the Durbin Watson statistics for this data was 2.00 which fall within the acceptable range from 1.50 to 2.50; therefore this analysis satisfied the assumption of independence and no autocorrelations. Multicollinearity assumption was checked through Variance Inflation Factor (VIF). The analysis showed VIF for each independent variable less than 10. Hence there was no evidence of Multicollinearity.

Bivariate linear regression analysis was performed and variable with $p$-value $<0.20$ was exported to multivariate linear regression analysis. Significance level was obtained at $95 \% \mathrm{CI}$ and $p$-value $<0.05$. The categorical independent variables were entered as dummy variables.

For qualitative data content analysis of the interview was performed. Tape recorded in depth interview was transcribed and then translated into English by two professionals. The translated material was read several times in order to get the general sense of the contents. Inductive approach was followed to allow the conceptual cluster of ideas and patterns to emerge. Then compared and reorganized into tentative categories. For the reporting of qualitative research we adhered to the COREQ guidelines.

\section{Results}

Of the total 637 questionnaires distributed to different departments in the 4 hospitals 596 completed and valid questionnaires were returned, which gives a response rate of $93.6 \%$.

\section{Demographic and socio-economic characteristics of the study participants}

From the total respondents, 367 (61.6\%) were males. The mean age with standard deviation of the respondents was $28.8 \pm 6$ years and the age of the study participants ranged from 21 to 57 years. Among 596 respondents, 301 (50.5\%) were nurses and 502 $(84.2 \%)$ respondents had less than or equal to 5 years of work experiences (See Table 1). Among the study participants, $92(15.4 \%)$ of them works in internal medicine department followed by surgical ward 91 $(15.3 \%)$ and 87 (14.6\%) of respondents works in many departments.

Of the total 596 study participants, 514 (86.2 \%) respondents had direct interaction or contact with the patients and $448(75.2 \%)$ of the respondents did not received any training on patient safety (See Table 2 ).

\section{Patient safety grade and Number of events reporting}

According to this study, $11 \%$ and $23 \%$ of the respondents rated the patient safety grade as excellent and very good, respectively. Among participants, $39 \%$ of 
Table 1 Demographic and socio-economic characteristics of the study participants in Jimma zone hospitals, Southwest Ethiopia, $2015(N=596)$

\begin{tabular}{lll}
\hline Variables & Frequency $(\mathrm{n})$ & Percent (\%) \\
\hline Sex & 367 & 61.6 \\
Male & 229 & 38.4 \\
Female & & \\
Age (years) & 407 & 68 \\
$\leq 29$ & 170 & 29 \\
$30-44$ & 19 & 3 \\
$\geq 45$ & & \\
Marital status & 291 & 48.8 \\
Single & 255 & 42.8 \\
Married & 50 & 8.4 \\
Divorced/Widowed & & \\
Religion & 253 & 42.4 \\
Orthodox & 169 & 28.4 \\
Muslim & 162 & 27.2 \\
Protestant & 12 & 2 \\
Others & &
\end{tabular}

Work experience in current hospital (years)

$\begin{array}{lll}\leq 5 & 502 & 84.2 \\ 6-10 & 58 & 9.7 \\ \geq 11 & 36 & 5.9\end{array}$

Profession

Nurse $\quad 301 \quad 50.5$

$\begin{array}{lll}\text { Medical doctor } & 88 & 14.8\end{array}$

Dentist $\quad 21 \quad 3.5$

Pharmacist $\quad 33 \quad 5.5$

$\begin{array}{lll}\text { Midwives } & 55 & 9.2\end{array}$

$\begin{array}{lll}\text { Psychiatrist } & 21 & 3.5\end{array}$

Lab technologist $\quad 35 \quad 5.9$

Others $^{\mathrm{b}} \quad 42 \quad 7.1$

Others $^{\mathrm{a}}$ : Catholic, Adventist, Waqefeta; others ${ }^{\mathrm{b}}=$ Anesthetist,

Optometry, Management

respondents rated patient safety grade as acceptable, while $21 \%$ and $6 \%$ of respondents rated the patient safety grade as poor and falling respectively.

Regarding number of events reported in the past 12 months the majority (69\%) of respondents never reported any event/error (See Additional file 3: Figure S1).

Comparative results on patient safety culture dimensions across Jimma zone hospitals

On 7 out of 12 patient safety culture dimensions, the 4 hospitals show significant differences in their score $(P$-Value $<0.05)$. These are teamwork within hospital departments, supervisor/manager expectations and
Table 2 Systemic factors and personal characteristics of the study participants in Jimma zone hospitals, Southwest Ethiopia, $2015(N=596)$

\begin{tabular}{lll}
\hline Variables & Frequency $(\mathrm{n})$ & Percent (\%) \\
\hline Direct contact with the patients & & \\
No & 82 & 13.8 \\
Yes & 514 & 86.2 \\
Patient safety training & \\
No & 448 & 75.2 \\
Yes & 148 & 24.8 \\
Participation in patient safety program & \\
Never & 298 & 50 \\
At least once per year & 298 & 50
\end{tabular}

Hospital management encourage reporting of events

$\begin{array}{lll}\text { No } & 392 & 65.8 \\ \text { Yes } & 204 & 342\end{array}$

Hospital management blame when medical errors happened

$\begin{array}{lll}\text { No } & 255 & 42.8\end{array}$

$\begin{array}{lll}\text { Yes } & 341 & 57.2\end{array}$

Hours worked per week (Hours)

$\begin{array}{lll}39-59 & 505 & 84.8 \\ \geq 60 & 91 & 15.2\end{array}$

We work together as a team

Strongly disagree/Disagree $\quad 54 \quad 9.1$

Neutral $25 \quad 4.2$

$\begin{array}{lll}\text { Agree/Strongly agree } & 517 & 86.7\end{array}$

There is adequate staffing

Strongly disagree/Disagree $\quad 315$

$\begin{array}{lll}\text { Neutral } & 79 & 13.3\end{array}$

$\begin{array}{lll}\text { Agree/Strongly agree } & 202 & 33.9\end{array}$

We communicate freely

$\begin{array}{lll}\text { Never/Rarely } & 297 & 49.8 \\ \text { Sometimes } & 125 & 21 \\ \text { Most of the time/Always } & 174 & 29.2\end{array}$

Exchange of feedbacks with each other

$\begin{array}{lll}\text { Never/Rarely } & 168 & 28.2 \\ \text { Sometimes } & 151 & 25.3 \\ \text { Most of the time/Always } & 277 & 46.5\end{array}$

actions promoting safety, organizational learning/ continuous improvement, hospital management support for patient safety, frequency of event reporting, teamwork across hospital departments and hospital handoffs and transitions. This variation might be due to the differences in location and size of hospitals, level of staffing, style of leadership, management strategy and relationships with in hospital staff between hospitals (See Table 3). 
Table 3 Comparative results on Patient safety culture dimensions across Jimma zone hospitals, Southwest Ethiopia, 2015

\begin{tabular}{|c|c|c|c|c|c|}
\hline \multirow[t]{2}{*}{ Patient safety culture dimensions } & \multicolumn{4}{|c|}{ average positive responses } & \multirow[t]{2}{*}{$P$-Value } \\
\hline & JUSH $(N=442)$ & $\mathrm{SGH}(N=54)$ & LGH $(N=58)$ & $\mathrm{AH}(\mathrm{N}=42)$ & \\
\hline Team work with in hospital & $82 \%$ & $89 \%$ & $79 \%$ & $80 \%$ & 0.038 \\
\hline Supervisor expectation & $47 \%$ & $60 \%$ & $48 \%$ & $45 \%$ & 0.024 \\
\hline Organizational learning & $74 \%$ & $75 \%$ & $55 \%$ & $60 \%$ & $<0.001$ \\
\hline Mgt support for patient safety & $41 \%$ & $49 \%$ & $50 \%$ & $40 \%$ & 0.021 \\
\hline Perception of patient safety & $50 \%$ & $58 \%$ & $47 \%$ & $52 \%$ & 0.199 \\
\hline Feedback \& communication about error & $35 \%$ & $31 \%$ & $22 \%$ & $29 \%$ & 0.095 \\
\hline Communication openness & $47 \%$ & $49 \%$ & $34 \%$ & $46 \%$ & 0.36 \\
\hline Frequency of event reporting & $28 \%$ & $31 \%$ & $21 \%$ & $20 \%$ & $<0.001$ \\
\hline Teamwork across hospital & $57 \%$ & $69 \%$ & $65 \%$ & $66 \%$ & 0.012 \\
\hline Staffing & $35 \%$ & $40 \%$ & $31 \%$ & $33 \%$ & 0.552 \\
\hline Handoffs and transitions & $43 \%$ & $50 \%$ & $34 \%$ & $29 \%$ & 0.032 \\
\hline Non punitive response to error & $23 \%$ & $28 \%$ & $30 \%$ & $17 \%$ & 0.163 \\
\hline
\end{tabular}

N sample size for each hospital, JUSH Jimma University Specialized Hospital, LGH Limu Genet Hospital, AH Agaro Hospital

\section{Overall level of patient safety culture}

The overall level of patient safety culture was $46.7 \%$ (95 \% CI: 43.0, 51.2). The dimension with the highest average percentage positive responses was teamwork within department (82\%). While the area with the most potential for improvement and the lowest average percentage positive responses was non-punitive response to error (23.7\%) (See Table 4$)$.

\section{Factors associated with patient safety culture}

The multivariable analysis model explained $59 \%$ of the variance in the patient safety culture (Adjusted $\mathrm{R}$ square $=0.59, P$-Value $<0.001)$.

Multivariate analysis showed that hours worked per week, level of staffing, teamwork within hospital, good communication, reporting an event, exchange of feedback about error and participation in patient safety program were found to be significantly associated with the patient safety culture (See Table 5).

\section{Finding from the qualitative study}

A total of 10 health care professionals were successfully interviewed. Of who interviewed 4 were nurses and others were from physicians, midwives and clinical pharmacy profession represented by 2 respondents from each.

The factors influencing patient safety culture as perceived by health care professionals were thematically categorized as system factors, health care professional factors and patient factors.

Table 4 Patient safety culture composite level results of Jimma zone hospitals, Southwest Ethiopia, 2015 ( $N=596)$

\begin{tabular}{llll}
\hline Patient safety culture dimensions & Number of Items & Cronbach's alpha & Positive safety culture score \\
\hline Teamwork within hospital departments & 4 & 0.802 & $82 \%(74-89)$ \\
Organizational learning & 3 & 0.79 & $71.3 \%(61-87)$ \\
Teamwork across hospital departments & 4 & 0.72 & $59.5 \%(49-70)$ \\
Overall perception of patient safety & 4 & 0.62 & $50.5 \%(36-62)$ \\
Supervisor expectation and action promoting safety & 4 & 0.63 & $48.5 \%(38-55)$ \\
Communication openness & 3 & 0.65 & $46 \%(45-47)$ \\
Hospital management support for patient safety & 3 & 0.68 & $42.7 \%(41-44)$ \\
Hospital handoffs and transitions & 4 & 0.81 & $41.5 \%(35-47)$ \\
Staffing & 4 & 0.608 & $35.25 \%(27-44)$ \\
Feedback and communication about error & 3 & 0.80 & $33 \%(28-37)$ \\
Frequency of event reporting & 3 & 0.88 & $27 \%(25-30)$ \\
Non punitive response to error & 3 & 0.74 & $23.7 \%(20-29)$ \\
Overall level of patient safety culture & 42 & 0.84 & $46.7 \%$ \\
\hline
\end{tabular}


Table 5 Factors associated with patient safety culture in Jimma zone hospitals, Southwest Ethiopia, 2015 (N=596) (Multivariate Linear Regression analysis)

\begin{tabular}{|c|c|c|c|c|}
\hline Variables & No. (\%) & Unstand. Coeff. ( $\beta$ ) & SE & $95 \% \mathrm{Cl}$ for $\beta$ \\
\hline \multicolumn{5}{|l|}{$\overline{\text { Sex }}$} \\
\hline Female $^{1}$ & $229(38.4)$ & 0 & & \\
\hline Male & $367(61.6)$ & -0.71 & 0.75 & $(-0.943,0.346)$ \\
\hline \multicolumn{5}{|l|}{ Age (years) } \\
\hline$\leq 29^{1}$ & $407(68)$ & 0 & & \\
\hline $30-44$ & $170(29)$ & 0.71 & 0.69 & $(-.644,2.058)$ \\
\hline$\geq 45$ & $19(3)$ & -.06 & 2.02 & $(-4.032,3.912)$ \\
\hline \multicolumn{5}{|l|}{ Direct contact with patients } \\
\hline $\mathrm{No}^{1}$ & $82(14)$ & 0 & & \\
\hline Yes & $514(86)$ & -0.82 & 0.96 & $(-2.701,1.071)$ \\
\hline \multicolumn{5}{|l|}{ Primary work department } \\
\hline Medical $^{1}$ & $92(15.4)$ & 0 & & \\
\hline Many different department & $87(14.6)$ & 0.45 & 0.99 & $(-1.507,2.415)$ \\
\hline Surgical & $91(15.3)$ & 1.75 & 0.97 & $(-0.162,3.654)$ \\
\hline Obstetrics & $66(11.1)$ & 3.32 & 1.80 & $(-0.216,6.861)$ \\
\hline Pediatrics & $48(8.1)$ & 0.29 & 1.14 & $(-1.939,2.534)$ \\
\hline Outpatient department & $41(6.9)$ & -1.59 & 1.21 & $(-3.964,0.788)$ \\
\hline Psychiatry/Mental health & $32(5.4)$ & 0.26 & 2.04 & $(-3.749,4.264)$ \\
\hline Intensive care unit & $27(4.5)$ & 1.63 & 1.47 & $(-1.248,4.509)$ \\
\hline Hours worked per week & $596(100)$ & -0.06 & 0.03 & $(-0.123,-0.001)^{*}$ \\
\hline \multicolumn{5}{|l|}{ Patient safety training } \\
\hline $\mathrm{No}^{1}$ & $448(75.2)$ & 0 & & \\
\hline Yes & $148(24.8)$ & -0.59 & 0.66 & $(-1.891,0.715)$ \\
\hline \multicolumn{5}{|l|}{ Years of experience at hospital } \\
\hline$\leq 5^{1}$ & $502(84.2)$ & 0 & & \\
\hline $6-10$ & $58(9.7)$ & -1.44 & 1.01 & $(-3.428,0.555)$ \\
\hline$\geq 11$ & $36(6.1)$ & -1.47 & 1.54 & $(-4.490,1.554)$ \\
\hline \multicolumn{5}{|l|}{ Adverse event report } \\
\hline $\mathrm{No}^{1}$ & $370(62.1)$ & 0 & & \\
\hline Yes & $226(37.9)$ & 3.34 & 0.62 & $(2.119,4.567)^{* *}$ \\
\hline Teamwork within hospital & $596(100)$ & 1.91 & 0.28 & $(1.366,2.457)^{* *}$ \\
\hline Communication with each other & $596(100)$ & 2.78 & 0.25 & $(2.285,3.284)^{* *}$ \\
\hline Level of staffing & $596(100)$ & 1.32 & 0.22 & $(0.885,1.746)^{* *}$ \\
\hline Feedback when error happened & $596(100)$ & 1.37 & 0.23 & $(0.914,1.831)^{* *}$ \\
\hline \multicolumn{5}{|l|}{ Management encouragement } \\
\hline $\mathrm{No}^{1}$ & $392(65.8)$ & 0 & & \\
\hline Yes & $204(34.2)$ & 0.88 & 0.64 & $(-0.372,2.125)$ \\
\hline \multicolumn{5}{|l|}{ Participation in patient safety program } \\
\hline $\mathrm{No}^{1}$ & $298(50)$ & 0 & & \\
\hline Yes & $298(50)$ & 1.30 & 0.37 & $(0.573,2.031)^{* *}$ \\
\hline
\end{tabular}




\section{System factors}

Respondents believed that event reporting system positively affect patient safety culture. Event reporting was described as one type of safety information system that relies on staff reports of errors, safety concerns, adverse events and near misses that occur within routine situations to learn from it. Event reporting was mentioned as an essential component by health care workers to improve learning culture and then patient safety culture. However, they highlighted that event reporting system was not established in the hospital and most of professionals in the hospital never reported the event.

"I remember one case when I had been working in surgical department, one patient dead due to health care professional mistakes but they kept silent about the case, you see it was forgotten now without learning from that mistakes and not sure the same mistakes will not occur in the future" (R09, Nurse)

Participants described shortage of supply and equipment as the factors which hinder patient safety culture. They highlighted shortage of water supply, lack of gloves, syringes, emergency drugs and cabinet shelves which seems simple but affecting the patient safety culture strongly.

"Sometimes gloves and syringes which seems simple were not found when we try to give medication" (R02, physician)

"In maternity department water supply is very necessary but there is shortage" (R01, Midwives)

Majority of respondents expressed as shortage of staff and high workload on health care professionals negatively affect the patient safety culture. They believed infrastructures of hospital and people served should be balanced to provide safe care.

“...For example, there is no personnel responsible for patient safety in this hospital, in developed countries I know there is risk management department, rather here limited to infection prevention"(R02, physician) "I am amazed that one physician should see up to 30 patients per day, how you can decide the length of duration for one case, this shows shortage of staff" (R03, physician)

\section{Health care professional's factors}

Respondents believed conflict between professionals and poor teamwork negatively affect patient safety culture. Collaboration of health professionals and respecting each other is an important factor. Some nurses reported lack of collaboration between physicians and non-physicians looked as a barrier to improve patient safety culture due to hierarchical differences.

"In my opinion patient safety is improved by teamwork/collaboration between health care professionals, but in this hospital I am afraid to say there is teamwork and respect between physicians and non-physicians professionals." (R04, Nurse)

The low attitude of healthcare professionals toward patient safety was reported to affect patient safety culture negatively. Respondents highlighted the perception of healthcare professionals on patient safety as very low.

"...When I say low attitude of health care professionals, I mean internal feeling/interest of professionals on patient safety culture is very low, this may affect the patient safety culture negatively" (R06, Nurse)

"I think health care professional's attitude toward patient safety is poor, this may be due to lack of training." (R03, Physician)

\section{Patient factors}

Patient perception about the health service provided and their interaction also influence the patient safety culture according to the respondents thought. Most of the respondents were reported as patient involvement is very important for achieving positive patient safety culture.

"Majority of patients do not know who to contact to get the service they need and do not interact while they feel unsafe in a situation, this might be due to lack of awareness of patient safety" (R08, Clinical pharmacist)

In general all respondents believed government, hospital management, each hospital staff and patient itself are responsible to achieve increased patient safety culture.

Increased awareness of patients on service, positive attitude of health care professionals on patient safety, improved communication between healthcare professionals, increased teamwork and adequate supply chain were important factors to achieve better patient safety culture as described by respondents.

\section{Discussion}

In this study the overall level of patient safety culture was found to be $46.7 \%$ (95 \% CI: 43.0, 51.2). This result showed that the hospitals had poor/low patient safety 
culture and areas with the most potential for improvement and needs urgent improvements. This result is comparable with the study reported $48 \%$ in India [23]. This similarity might be due to the similarities in staffing and hospital infrastructure between countries.

However, the overall level of patient safety culture of this study is lower when compared with the study reported, $51.75 \%$ in Japan [24], $52.2 \%$ in Netherlands [25], $52.9 \%$ in Taiwan [24], $52.8 \%$ in Iran [26], $62 \%$ in USA [25], $62.7 \%$ in Srilanka [27], 64 \% in another study conducted in Taiwan [14] and $65 \%$ in China [28]. This difference might be due to the differences in organizational behavior between countries. Those countries might have better management values, organizational commitments, leadership and relationships within hospital staff. Other possible reasons might be due to high economic development and those countries were initiated patient safety issue early compared to our country.

In this study 'teamwork within department' and 'organizational learning' dimensions were area of strength with average positive response rate of $82 \%$ and $71.3 \%$ respectively. This indicates respondents are positive in supporting one another, working together as a team and doing things to improve patient safety.

Although respondents generally described as there is good team work within departments, poor communication and collaboration between professions within hospitals was described by few respondents during the in depth interview. This weak communication was explained due to hierarchical differences. This result is in line with the finding of a qualitative study in two African hospitals [29]. This result indicates patient safety culture is influenced by the norms and values of professional thought and efforts to regain status.

The areas with the most potential for improvement in this study area were 'non punitive response to error' and 'frequency of event reporting' with average positive response rate of $23.7 \%$ and $27 \%$ respectively. This result suggest healthcare workers in this study area feel that their mistakes and event reports are held against them and that mistakes are kept in their personal file.

Dimensions like 'feedback and communication about error,' 'Staffing,' 'Hospital handoffs and transitions', 'hospital management support for patient safety', 'communication openness' and 'supervisor/manager expectation and actions promoting safety' were areas with potential for improvement with average positive response rate of $33 \%$, $35.25 \%, 41.5 \%, 42.7 \%, 46 \%$ and $48.5 \%$ respectively. This finding highlights deficiencies in many patient safety culture dimensions and indicates presence of low patient safety practice in the study area.

For every unit increase in hours worked per week the patient safety culture score found to reduce by 0.06 ( $\beta=$ $-0.06,95$ \% CI:-0.12,-0.001). This result strengthened by qualitative findings where respondents believed when healthcare professionals work longer hours they try to work faster than best for patient care. This may be explained as when hospital staff worked longer hours, the way of working by trying to do too quickly may have negative impact on performance, and consequently has poor patient safety culture.

This study showed, respondents who report an event/ error either orally or in written form increase the score of patient safety culture by 3.34 compared to respondents not reporting an event ( $\beta=3.34,95 \%$ CI: $2.12,4.57)$. This result is also supported by the qualitative finding, in which respondents believed reporting an event has a positive impact on patient safety culture. This finding is in line with the result reported in Lebanon [19] and Sweden [18]. This might be due to the truth that event reporting systems generate useful information to address weakness in work systems and processes, so it provides an opportunity to improve the patient safety culture.

Participating in patient safety program increased the patient safety culture score by 1.3 ( $\beta=1.3,95 \%$ CI: 0.57 , 2.03). This result is in line with the study reported in Sweden [30]. This result might be explained as the staff used more times on patient safety issues in patient safety program, this situation favor them to deal more with patient safety culture.

This study found that a one unit increase in the score on teamwork within hospital improved the patient safety culture score by 1.91 ( $\beta=1.91,95 \% \mathrm{CI}: 1.37,2.46)$. The findings from qualitative study also support these results, respondents felt increased teamwork and collaboration between health care professionals improves patient safety culture. This finding is similar with studies conducted in Lebanon [19] and Riyadh [31], which reported as teamwork within department increase perception of patient safety culture. This might be explained as higher score on people support one another, working together as a team and respecting each other improve the patient safety culture.

According to this study, for every unit increase on the score of communication with each other the patient safety culture score improved by $2.78(\beta=2.78,95 \%$ CI: 2.29 , 3.28). This finding is again in line with the study in Lebanon [19], which state higher score on communication openness increase perception of patient safety culture. But the study in Riyadh [31] had showed for a one unit increase in communication openness was associated with lower perception of patient safety culture. This variation might be due to the difference in the national culture of the countries.

As per this study, overall patient safety culture score improved by 1.32 for every unit increase in the score on level of staffing ( $\beta=1.32,95 \% \mathrm{CI}$ : $0.89,1.75)$. The result is analogous to study conducted in Lebanon [19] and 
Riyadh [31], where higher score on staffing associated with improved perception of patient safety culture. This finding may indicate as staffs within departments adequate to handle the workload the patient safety culture could be improved.

Similarly the finding from the qualitative approach showed shortage of staff in the hospitals negatively affects the patient safety culture. As the staff works additional or extra-long times the probability of practicing better patient safety culture is low. This finding is in line with result of the qualitative study conducted in two African hospitals [29]. This result suggests hospitals in African regions are characterized by shortage of staff.

Based on this study for every unit increase in exchange of feedback when error happened increases the score on patient safety culture by $1.37(\beta=1.37,95 \% \mathrm{CI}: 0.91$, 1.83). This finding is supported by the qualitative results; where respondents believed investigation of the root cause of error and exchange of comprehensive feedback of error improve the patient safety culture.

From the qualitative finding respondents believed patient involvement and health care professional's attitude toward patient safety influence patient safety culture. This result is supported by qualitative study conducted in Sweden [30].

Since we assessed patient safety culture from hospitals staff opinion, the possibility of under or over reporting could not be ruled out. But through honestly explaining the objective and significances of the study we tried to minimize the effect.

\section{Conclusions}

The finding of this study showed that the overall level of patient safety culture in Jimma zone hospitals found to be low.

Hours worked per week, adverse event reporting, good communication, teamwork within hospital, level of staffing, exchange of feedback about error and participating in patient safety program were factors significantly associated with the patient safety culture. Hours worked per week, incident reporting, teamwork, level of staffing and exchange of feedback about error were supported by the qualitative finding.

While shortage of resource, healthcare professional attitude toward patient safety and patient involvement were additional variables explored as important factors that influence patient safety culture during in depth interview.

\section{Additional files}

Additional file 1: Questionnaire to assess Patient Safety Culture and Associated Factors. The HSOPSC was used to collect quantitative data on patient safety culture. The questionnaire was classified into 3 parts and * part questions were added when adapting HSOPSC. (DOCX 53 kb)
Additional file 2: Semi structured interview guide questions. The in depth interview was focused to identify factors influencing patient safety culture. (DOCX $14 \mathrm{~kb}$ )

Additional file 3: Figure S1. Number of events reported by respondents in Jimma zone hospitals, Southwest Ethiopia, 2015 ( $N=596)$. (DOCX $14 \mathrm{~kb})$

\section{Abbreviations}

HSOPSC: Hospital survey on patient safety culture; SPSS: Statistical package for social science; USA: United State of America; VIF: Variance inflation factor

\section{Acknowledgments}

I would like to thank Hacalu Layesa (M.Sc.) and Sisay Adamu (BSc) for their kind support and assistance in the development of this study. I would also like to express my gratitude to supervisors, data collectors and the entire study participants for their full participation in the study.

\section{Funding}

There is no source of funding for this study.

\section{Availability of data and materials}

All data generated or analyzed during this study are included in this article. The data that support the findings of this study are also available from the corresponding author upon reasonable request.

\section{Authors' contributions}

SDW contributed to the study design, data collection, data analysis, interpretations of the results and manuscript write-up. AFD and MMW contributed to data analysis, interpretations of the results and manuscript writeup and review. ANA made substantial contributions to interpretations of results and manuscript write-up and review. All authors read and approved the final manuscript.

\section{Competing interests}

There is no any financial and non-financial competing interest.

\section{Consent for publication}

Privacy and confidentiality of information given by each respondent was kept properly and personal identifiers were removed.

\section{Ethics approval and consent to participate}

Ethical clearance was obtained from Ethical Review Committee of Institute of Public Health, College of Medicine and Health Sciences, University of Gondar Permission letter was also obtained from each hospital Chief Executive Officer. Those health care workers in the Jimma zone hospitals, who were selected to participate, were informed about the purpose of the study, the importance of their participation and withdraw at any time. Written consent was obtained prior to quantitative data collection. Verbal consent was obtained prior to interview.

\section{Author details}

${ }^{1}$ Department of Environmental and Occupational Health and Safety, Institute of Public Health, University of Gondar, Gondar, Ethiopia. ${ }^{2}$ Department of Health Service Management and Health Economics, Institute of Public Health, University of Gondar, Gondar, Ethiopia. ${ }^{3}$ Department of Human Nutrition, Institute of Public Health, University of Gondar, Gondar, Ethiopia.

Received: 22 August 2015 Accepted: 14 September 2016

Published online: 20 September 2016

\section{References}

1. Makeham MA, Kidd MR, Saltman DC, Mira M, Bridges-Webb C, Cooper C, Stromer S. The Threats to Australian Patient Safety (TAPS) study: incidence of reported errors in general practice. Med J Aust. 2006;185(2):95.

2. Nieva V, Sorra J. Safety culture assessment: a tool for improving patient safety in healthcare organizations. Qual Saf Health Care. 2003;12:ii17-23.

3. Woods DM, Thomas EJ, Holl JL, Weiss KB, Brennan TA. Ambulatory care adverse events and preventable adverse events leading to a hospital admission. Qual Saf Health Care. 2007;16(2):127-31. 
4. Zwart D, Langelaan M, Kuyvenhoven M, KaLKMan C. 3 Exploration of patient safety culture perceptions in Dutch general practice. A cross sectional survey. In: Incident reporting in general practice. 2011. p. 47.

5. Zwart DL, Langelaan M, Van de Vooren RC, Kuyvenhoven MM, Kalkman CJ, Verheij TJ, Wagner C. Patient safety culture measurement in general practice. Clinimetric properties of 'SCOPE'. BMC Fam Pract. 2011;12(1):117.

6. Sorra JS, Dyer N. Multilevel psychometric properties of the AHRQ hospital survey on patient safety culture. BMC Health Serv Res. 2010;10(1):199.

7. Sorra J, Nieva V. Hospital Survey on Patient Safety Culture. AHRQ Publication No. 04-0041. Rockville: Agency for Healthcare Research and Quality; 2007.

8. Powell S, Baily D, Njide Ndili M, Ente C. Patient Safety in Africa: A Culture Shift? 2011.

9. Carpenter K, Duevel M, Lee P, Wu A, Bates D, Runciman W, Baker G, Larizgoitia I, Weeks W. Measures of patient safety in developing and emerging countries: a review of the literature. Qual Saf Health Care. 2010;19(1):48-54.

10. Assefa T, Woldie M, Ololo S, Woldemichael K. Patient safety practices and medical errors: Perception of health care providers at Jimma University Specialized Hospital, Southwest Ethiopia. 2012.

11. Jha AK, Larizgoitia I, Audera-Lopez C, Prasopa-Plaizier N, Waters H, Bates DW. The global burden of unsafe medical care: analytic modelling of observational studies. BMJ Qual Saf. 2013;22(10):809-15.

12. Wilson R, Michel P, Olsen S, Gibberd R, Vincent C, El-Assady R, Rasslan O, Qsous S, Macharia W, Sahel A. Patient safety in developing countries: retrospective estimation of scale and nature of harm to patients in hospital. BMJ. 2012;344:e832.

13. Nejad SB, Allegranzi B, Syed SB, Ellis B, Pittet D. Health-care-associated infection in Africa: a systematic review. Bull World Health Organ. 2011;89(10):757-65.

14. Chen $\mathrm{I}-\mathrm{C}$, $\mathrm{Li} \mathrm{H}-\mathrm{H}$. Measuring patient safety culture in Taiwan using the Hospital Survey on Patient Safety Culture (HSOPSC). BMC Health Serv Res. 2010;10(1):152

15. Gehring K, Schwappach DL, Battaglia M, Buff R, Huber F, Sauter P, Wieser M. Safety climate and its association with office type and team involvement in primary care. Int J Qual Health Care. 2013;25(4):394-402.

16. Kohn LT, Corrigan JM, Donaldson MS. To Err Is Human:: Building a Safer Health System. Washington: National Academies Press; 2000.

17. Sexton J, Helmreich R, Neilands T, Rowan K, Vella K, Boyden J, Roberts P, Thomas EJ. The Safety Attitudes Questionnaire: psychometric properties, benchmarking data, and emerging research. BMC Health Serv Res. 2006;6:1-44.

18. Nygren M, Roback K, Öhrn A, Rutberg H, Rahmqvist M, Nilsen P. Factors influencing patient safety in Sweden: perceptions of patient safety officers in the county councils. BMC Health Serv Res. 2013;13(1):52.

19. El-Jardali F, Dimassi H, Jamal D, Jaafar M, Hemadeh N. Predictors and outcomes of patient safety culture in hospitals. BMC Health Serv Res. 2011;11(1):45

20. Walston SL, Al-Omar BA, Al-Mutari FA. Factors affecting the climate of hospital patient safety: A study of hospitals in Saudi Arabia. Int J Health Care Qual Assur. 2010;23(1):35-50.

21. Henriksen K, Battles JB, Keyes MA, Grady ML, Jones KJ, Skinner A, Xu L, Sun J, Mueller K. The AHRQ hospital survey on patient safety culture: a tool to plan and evaluate patient safety programs. 2008.

22. Sorra J, Nieva V. Hospital survey on patient safety culture. (Prepared by Westat, under contract no. 290-96-0004). AHRQ publication no. 04-0041. Rockville: Agency for Healthcare Research and Quality; 2004.

23. Rao M, Thota D, Srinivas P. A Study to Assess Patient Safety Culture amongst a Category of Hospital Staff of a Teaching Hospital. IOSR J Dent Med Sci. 2014;13:3

24. Fujita S, Seto K, Ito S, Wu Y, Huang C-C, Hasegawa T. The characteristics of patient safety culture in Japan, Taiwan and the United States. BMC Health Serv Res. 2013;13(1):20.

25. Wagner C, Smits M, Sorra J, Huang C. Assessing patient safety culture in hospitals across countries. Int J Qual Health Care. 2013;25(3):213-21.

26. Mohammadreza A, Sogand T, Omid B. Measuring safety culture and setting priorities for action at an Iranian hospital. Al Ameen J Med Sci. 2010;3(3):237-45.

27. Amarapathy M, Sridharan S, Perera R, Handa Y. Factors Affecting Patient Safety Culture In A Tertiary Care Hospital In Sri Lanka. Int J Sci Technol Res. 2013;2:3.

28. Nie Y, Mao X, Cui H, He S, Li J, Zhang M. Hospital survey on patient safety culture in China. BMC Health Serv Res. 2013;13(1):228.
29. Aveling E-L, Kayonga Y, Nega A, Dixon-Woods M. Why is patient safety so hard in low-income countries? A qualitative study of healthcare workers views in two African hospitals. BioMed Central. 2015;11:6.

30. Ridelberg M, Roback K, Nilsen P. Facilitators and barriers influencing patient safety in Swedish hospitals: a qualitative study of nurses' perceptions. BMC Nurs. 2014;13(1):23.

31. El-Jardali F, Sheikh F, Garcia NA, Jamal D, Abdo A. Patient safety culture in a large teaching hospital in Riyadh: baseline assessment, comparative analysis and opportunities for improvement. BMC Health Serv Res. 2014;14(1):122.

\section{Submit your next manuscript to BioMed Central and we will help you at every step:}

- We accept pre-submission inquiries

- Our selector tool helps you to find the most relevant journal

- We provide round the clock customer support

- Convenient online submission

- Thorough peer review

- Inclusion in PubMed and all major indexing services

- Maximum visibility for your research

Submit your manuscript at www.biomedcentral.com/submit
) Biomed Central 